\title{
ANÁLISE DOS ACIDENTES COM SERPENTES NO MUNICÍPIO DE ESTREITO MARANHÃO, CIDADE SOB INFLUÊNCIA DIRETA DA USINA HIDRELÉTRICA ESTREITO.
}

\author{
ANALYSIS OF ACIDENTES WITH SERPENTES IN THE MUNICIPALITY OF ESTREITO \\ MARANHÃO, CITY UNDER THE DIRECT INFLUENCE OF THE ESTREITO HPP
}

\begin{abstract}
Helierson Gomes ${ }^{1}$, Andrielly Gomes de Jesus ${ }^{2}$, Erivaldo da Silva Soares Filho ${ }^{3}$. Patrícia Rogalski Lima ${ }^{3}$, Ludmilla Carolinne Santana Correia ${ }^{4}$.
\end{abstract}

\section{RESUMO}

Estudo realizado com objetivo de obter uma avaliação ambiental e epidemiológica dos casos de acidentes ofídicos no município de Estreito Maranhão, cidade sob influência direta da UHE Estreito. Trata-se de uma pesquisa do tipo quantitativa, epidemiológica, descritiva. Foram analisados neste período números absolutos dos casos (n), incidência (In), média (Me), percentual (\%) e variáveis específicas do perfil social como: faixa etária, sexo e raça. Para análise das características específicas dos acidentes foi utilizado dados do tipo de serpente, tempo entre acidente e o atendimento e classificação do caso e sua relação com fatores ambientais como temperatura e precipitação acumulada. No município de Estreito os acidentes ofídicos caracterizaramse por apresentarem maior incidência no período após o enchimento total do lago reservatório (2011 a 2015), sendo homens em idade produtiva (20 a 59 anos) os mais acometidos, e o gênero botrópico o de maior incidência. Vale a pena ressaltar o grande aumento (200\%) dos casos de acidente com Crotálico em relação ao período durante as obras para após a conclusão da UHE.

Palavras-chave: Acidenteofídicos; Hidrelétrica; Estreito-MA.

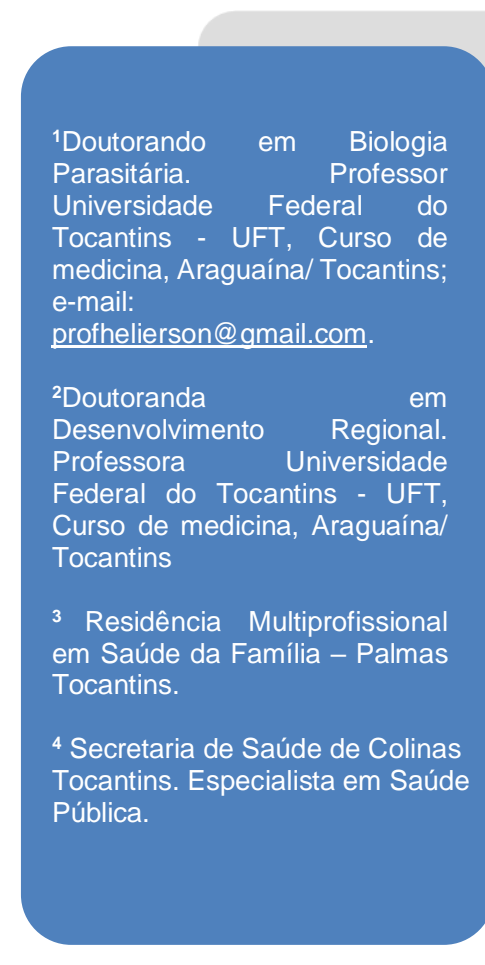

\section{ABSTRACT}

This research was conducted with the objective of obtaining an environmental and epidemiological evaluation of the cases of snakebite accidents in the city of Estreito Maranhão, a city directly influenced by the Estreito HPP. This is a quantitative, epidemiological, descriptive research. Absolute case numbers (n), incidence (In), mean $(\mathrm{Me})$, percentage (\%) and specific social profile variables such as age group, gender and race were analyzed during this period. For the analysis of the specific characteristics of the accidents, we used data on the type of snake, time between accident and the attendance and classification of the case and its relationship with environmental factors such as temperature and accumulated precipitation. In the city of Estreito, ophidian accidents were characterized by having a higher incidence in the period after the reservoir lake was completely filled (2011 to 2015), with men of productive age (20 to 59 years) being the most affected, and the botanic genus being higher incidence. It is worth mentioning the large increase (200\%) of the cases of accidents with Crotalic in relation to the period during the works until after the conclusion of the HPP.

Keywords: Accident accidents; Hydroelectric; Strait-MA.

\section{INTRODUÇAO}

Nos dias de hoje a eletricidade possui papel vital para o desenvolvimento socioeconômico das nações, diante do constante e intenso processo de industrialização 
brasileira, projetos, como as grandes hidrelétricas que são consideradas como fontes renováveis de energia, ganham papel de destaque tanto a produção de energia elétrica como seus impactos advindos dessa modernização, no entanto, ao desenvolver os modelos energéticos deve-se considerar seus impactos de ordem social e ambiental. (BORTOLETO, 2001.; SANCHES; FISCH, 2005).

As consequências provocadas pelo desenvolvimento econômico são impactantes, direta ou indiretamente na saúde e no meio ambiente, deixado pelas construções desse tipo de empreendimento, elas se dividem em diversas etapas sendo eles; os abalos sociais, urbanos e ambientais principalmente no período de construção, quando o deslocamento populacional é continuo e intenso, chegando a gerar imensos transtornos devido à precariedade de infraestrutura para acolher a demanda populacional, ocasionando a não oferta de vagas em escolas, saneamento básico, tráfico de drogas, prostituição, violência, acidentes de trânsito, crescimento desordenado de áreas periféricas entre outros. (GIONGO, 2015.; GOMES et al., 2016).

As modificações ambientais causadas pelas usinas hidrelétricas (UHE's) envolvem vários aspectos ecológicos extremamente complexos, como desvio de cursos d'agua, supressão de vegetação, deslocamento de animais em função do acolhimento do reservatório, criando-se um novo ambiente no local com instabilidade ecológica e social em função das desapropriações de terras (SOUSA, 2011).

Após a formação do lago reservatório algumas características limnológicas se alteram, como é o caso do processo de eutrofização, que é ocasionado pela quantidade de matéria orgânica em decomposição, esgotos não tratados, resíduos líquidos e sólidos nas águas dos lagos e represas geradas pelas hidrelétricas (NOGUEIRA, 2015). A eutrofização pode ter como consequência uma alteração das características químicas e físicas do meio, podendo trazer consequências negativas para o ecossistema aquático como a morte de diversos organismos (TUNDISI, 2003; TRINDADE, 2014).

Suas alterações advindas das inundações das áreas povoadas para a formação de um reservatório provocam diversos problemas, devido fatores determinantes que ocorre durante o avanço da água para enchimento do reservatório.

Os reservatórios das hidrelétricas funcionam como uma verdadeira fábrica de emissões de gazes efeito estufa (GEE), e um dos principais para efeito estufa é o metano $(\mathrm{CH} 4)$. Sendo produzido através do enchimento do reservatório. Segundo Maria e Zanoni et al., (2015), quando as plantas crescem tiram o carbono do ar em forma de gás carbônico 
(CO2) pela fotossíntese e quando morrem inundadas elas devolvem este carbono em forma de metano formado pela decomposição anaeróbica da matéria orgânica que fica enraizada no fundo dos reservatórios, sendo emitido na interface água/ar através de micro bolas ou difusão (FEARNSIDE, 2011).

Após a maturação do lago manifestações ecossistêmicas relacionadas a alterações microclimáticas também são características presentes neste cenário, alterações em todo o ciclo hidrológico e mudanças microclimáticas levam ao aumento da pluviosidade e precipitações, fazendo com que ocorra antecipação do início da estação chuvosa, e tornando-as mais leves e esparsas em toda a área de influência, afetando direta ou indiretamente a todos os que de certa forma praticam qualquer que seja a atividade baseado na característica climática da região (SANCHES, 2005).

O alagamento dos habitats naturais de diversas espécies de animais obriga o deslocamento dos mesmos para novos habitats naturais em busca refúgio e alimentos, levando sua migração em direção as proximidades das cidades podendo acarretar em um aumento dos índices de acidentes causados por picadas de animais peçonhentos e o surgimento de doenças infecciosas antes não endêmicas nessas regiões. (QUEIROZ, 2012., GOMES et al., 2014).

Essa intensa migração populacional e faunística torna o ambiente propício ao risco de acidentes com serpentes, tornando o acidente ofídico cada vez mais importante no que se refere a saúde pública nessas regiões (FURTADO, 2008).

Segundo estudos de Silva, et al (2015), o número de pessoas que sofrem envenenamentos no Brasil causados por serpentes representam aproximadamente 29 mil casos por ano com média de 125 óbitos anuais.

De acordo com Castro (2015), no Brasil a quantidade de acidentes ofídicos por serpentes dos gêneros Bothrops é de $87 \%$, Crotalus $9 \%$, Lachesis 3\% e Micrurus 1\%. A ocorrência dos acidentes ofídicos, em geral, está relacionado diretamente com os fatores climáticos e aumento da atividade humana nos trabalhos no campo (FUNASA, 2001).

O aumento dos índices de chuva leva os transbordamentos de corpos d'água, leitos de rios, igarapés e açudes, fazendo com que a serpentes procurem por terra firme e assim levando o aumento de encontro de serpentes com a população (SILVA, et al., 2015)

A Usina Hidrelétrica (UHE) Estreito está localizada na região Norte do Brasil, no Rio Tocantins, na divisa dos estados do Tocantins e Maranhão. A barragem e demais estruturas associadas estão situadas nos Municípios de Estreito no estado do Maranhão e 
Aguiarnópolis e Palmeiras do Tocantins ambas no estado do Tocantins. A UHE Estreito fica a 766 km da capital do Estado do Maranhão, São Luís e a 513 km da capital do Estado do Tocantins, Palmas. A usina foi projetada para uma vida útil superior a 100 anos, pois possui um reservatório de $260,23 \mathrm{~km}^{2}$ de extensão em áreas inundadas de 400 km² de extensão, afetando diretamente um total de 12 municípios dois no estado do maranhão (Estreito e Carolina) e 10 no estado do Tocantins (Aguiarnópolis, Babaçulândia, Barra do Ouro, Darcinópolis, Filadélfia, Goiatins, Itapiratins, Palmeirante, Palmeiras do Tocantins, Tupiratins). (CESTE, 2016., GOMES et al., 2016).

Esta pesquisa foi realizada com objetivo de obter uma avaliação ambiental e epidemiológica dos casos de acidentes ofídicos no município de Estreito Maranhão, cidade sob influência direta da UHE Estreito.

\section{MATERIAIS E METODOS}

Trata-se de uma pesquisa do tipo quantitativa, epidemiológica, descritiva e analítica, realizada no município de Estreito estado do Maranhão, cidade sob influência da construção da UHE Estreito.

Estreito trata-se de um município localizado mesorregião do Sul Maranhense possui uma área de $2.719 \mathrm{~km}^{2}$, conta com 40.629 habitantes, apresenta uma densidade demográfica de 13,1 habitantes tendo como bioma predominante o Cerrado.

Os dados foram coletados em três períodos. O primeiro período é referente à época que antecede a construção da usina (2001-2005), o segundo compreende a fase de construção e implantação (2006-2010), e o terceiro período é referente a fase após a implantação da usina hidrelétrica, já com toda a área do lago sob inundação (2011-2015). Para haver uma padronização geral, será coletado as médias dos casos confirmados (CC) e a incidência (In) nos períodos.

Foram analisados neste período números absolutos dos casos (n), incidência (In), média $(\mathrm{Me})$, percentual (\%) e variáveis específicas do perfil social como: faixa etária, sexo e raça. Para análise das características específicas dos acidentes foi utilizado dados do tipo de serpente, tempo entre acidente e o atendimento e classificação do caso.

Os dados epidemiológicos dos acidentes ofídicos foram coletados por meio do Sistema de informação de agravos notificados (SINAN), os dados geográficos e populacionais através do Instituto brasileiro de geografia e estatística (IBGE). 
Os dados serão tabulados e analisados com auxílio do software Microsoft Excel e MINITAB 17.0. Foi realizado as análises estatística descritiva e de variação um fator (ANOVA One Way) entre os períodos de estudo tendo como valor para referência de significância quando $p$ for menor que 0,05. Posteriormente será realizado o teste de Tukey, considerando o intervalo de confiança igual a 0,95. Para a análise de relação entre as características ambientais locais e a ocorrência dos acidentes foi utilizado o teste de correlação de Pearson tendo como valor de referência para o grau de relação segundo Dancey e Reidy (2006): $r=0,10$ até 0,30 (fraco); $r=0,40$ até 0,6 (moderado); $r=0,70$ até 1 (forte).

\section{RESULTADOS}

Tabela 1. Sazonalidade Acidentes ofídicos por período.

\begin{tabular}{lccccccccccccc}
\hline Ano/Mês & Jan & Fev & Mar & Abr & Mai & Jun & Jul & Ago & Set & Out & Nov & Dez & TOTAL \\
\hline Pré-UHE & 6 & 3 & 2 & 2 & 3 & 4 & 7 & 0 & 2 & 3 & 1 & 6 & $\mathbf{3 9}$ \\
Dur-UHE & 7 & 1 & 2 & 1 & 5 & 3 & 1 & 2 & 0 & 0 & 3 & 6 & $\mathbf{3 1}$ \\
Pós-UHE & 5 & 12 & 5 & 10 & 8 & 10 & 7 & 4 & 4 & 5 & 8 & 5 & $\mathbf{8 3}$ \\
\hline Total & $\mathbf{1 8}$ & $\mathbf{1 6}$ & $\mathbf{9}$ & $\mathbf{1 3}$ & $\mathbf{1 6}$ & $\mathbf{1 7}$ & $\mathbf{1 5}$ & $\mathbf{6}$ & $\mathbf{6}$ & $\mathbf{8}$ & $\mathbf{1 2}$ & $\mathbf{1 9}$ & $\mathbf{1 5 3}$
\end{tabular}

Fonte: SINAN/SVS/SMS, 2016.

Durante o período estudado houve um total de 153 casos de acidentes com serpentes no município de Estreito, apesar de alterações na incidência dos casos, tendo uma sutil elevação nos meses chuvosos ainda sim não existe uma variação significativa em relação aos demais meses do ano, apresentando uma distribuição pouco variante em todos os períodos analisados (Tabela 1).

Indiferente de outros estudos o gênero com maior prevalência foi o Botrópico com $78 \%$ dos casos notificados no período, fato este que não gera alarme por características ambientais e epidemiológicas da região, em contra partida o gênero Crotálico apresentando $14 \%$ dos casos representa valores acima da média nacional e regional para o gênero. As notificações de acidentes com Laquético e Elapídico apresentaram prevalência dentro do esperado para a região (Tabela 2). 
Tabela 2. Perfil dos acidentes ofídicos por gênero.

\begin{tabular}{|c|c|c|c|c|c|c|}
\hline \multirow{2}{*}{$\begin{array}{l}\text { Período/ } \\
\text { Acidente }\end{array}$} & \multicolumn{2}{|c|}{ Pré-UHE } & \multicolumn{2}{|c|}{ Dur-UHE } & \multicolumn{2}{|c|}{ Pós-UHE } \\
\hline & $n$ & $\%$ & $\mathbf{n}$ & $\%$ & $\mathbf{n}$ & $\%$ \\
\hline \multicolumn{7}{|l|}{ Sexo } \\
\hline Masculino & 25 & 75 & 21 & 62 & 65 & 74 \\
\hline Fem inino & 7 & 25 & 13 & 38 & 22 & 26 \\
\hline \multicolumn{7}{|l|}{ Faixa etária } \\
\hline$<10$ & 4 & 11 & 3 & 9 & 17 & 20 \\
\hline 10 a 19 & 7 & 21 & 12 & 38 & 4 & 5 \\
\hline 20 a 59 & 16 & 47 & 14 & 44 & 52 & 59 \\
\hline$>60$ & 7 & 21 & 3 & 9 & 14 & 16 \\
\hline \multicolumn{7}{|l|}{ Gênero } \\
\hline Botrópico & 24 & 15.6 & 25 & 16.3 & 70 & 45.7 \\
\hline Crotálico & 4 & 2.6 & 4 & 2.6 & 12 & 7.8 \\
\hline Laquético & 4 & 2.6 & 2 & 1.3 & 2 & 1.3 \\
\hline Elapídico & 0 & 0 & 0 & 0 & 1 & 0.6 \\
\hline Botrópico & 24 & 15.6 & 25 & 16.3 & 70 & 45.7 \\
\hline
\end{tabular}

Fonte: SINAN/SVS/SMS, 2016.

Em relação as características ambientais da região, estas mantiveram-se de acordo com o perfil ambiental local. Apesar da diminuição das notificações em meses com menores índices pluviométricos não houve relação significativa $(r=0.3)$ em relação aos acidentes ofídicos com os índices de precipitação acumulada o mesmo não ocorrendo com a temperatura média, esta apresentando uma forte relação $(r=0.78)$ entre os meses com menor temperatura e os acidentes com serpentes (Tabela 3).

Tabela 3. Sazonalidade dos acidentes ofídicos e relação com manifestações ambientais.

\begin{tabular}{lcccccccccccc}
\hline Ano/Mês & Jan & Fev & Mar & Abr & Mai & Jun & Jul & Ago & Set & Out & Nov & Dez \\
\hline $\begin{array}{c}\text { Acidente } \\
\text { ofídicos }\end{array}$ & 18 & 16 & $\mathbf{9}$ & $\mathbf{1 3}$ & $\mathbf{1 6}$ & $\mathbf{1 7}$ & $\mathbf{1 5}$ & $\mathbf{6}$ & $\mathbf{6}$ & $\mathbf{8}$ & $\mathbf{1 2}$ & $\mathbf{1 9}$ \\
$\begin{array}{c}\text { Precipitação } \\
\text { cumulada (mm) }\end{array}$ & 291.1 & 327.8 & 311.7 & 265.6 & 102 & 8.1 & 6.3 & 4.1 & 34.5 & 129.6 & 185.4 & 262.2 \\
$\begin{array}{c}\text { Temperatura } \\
\text { média }\end{array}$ & 34.2 & 34.1 & 34.3 & 34.8 & 35.6 & 36.9 & 38.4 & 40 & 40.5 & 38 & 35.4 & 31.4 \\
\hline
\end{tabular}

Fonte: SINAN; SISAM; BDMEP. 2016. 


\section{DISCUSSAO}

A construção de grandes empreendimentos em regiões pouco desenvolvidas veem se tornando uma atividade cada vez mais presente nas cidades brasileiras, em se tratando de UHE's estas por sua vez geram uma falsa sensação de desenvolvimento local durante o período de construção devido a grande injeção de recursos na economia local, rápido aumento populacional, entre outros. No município de Estreito não foi diferente onde houve um acréscimo populacional de 74\% entre os anos de 2001 a 2015 passando de 23.361 para aproximadamente $41 \mathrm{mil}$ habitantes. Esse processo gera um desequilíbrio social devido a hiperinflação imobiliária local induzindo o crescimento rápido e desordenado de áreas periféricas (GOMES, 2014., IBGE, 2016).

Após o término das obras acontece o efeito inverso rápida evasão e desocupação das pessoas e empresas vinculadas a UHE, gerando desemprego em massa, queda brusca na economia local e a chamada desterritorialidades, reterritorialidades e novas territorialidades todas vinculadas a territorialização do capital global deixando sempre em segundo plano os interesses sociais e os valores culturais da região (CHAVES e LIRA, 2008).

Em relação ao perfil das vítimas, homens em idade produtiva foram os mais acometidos, corroborando com estudos realizados por Pardal, (1995) confirmado por Albuquerque (2002), onde trabalhadores principalmente de atividades no meio rural são os mais suscetíveis a esse tipo de acidente laboral, alinhado ao período de busca de alimentos e desova das serpentes do Gênero Botrophs que ocorre em período semelhante ao de colheita de produtos agrícolas cultivados em grande escala na região, caso da soja, milho feijão, arroz etc.

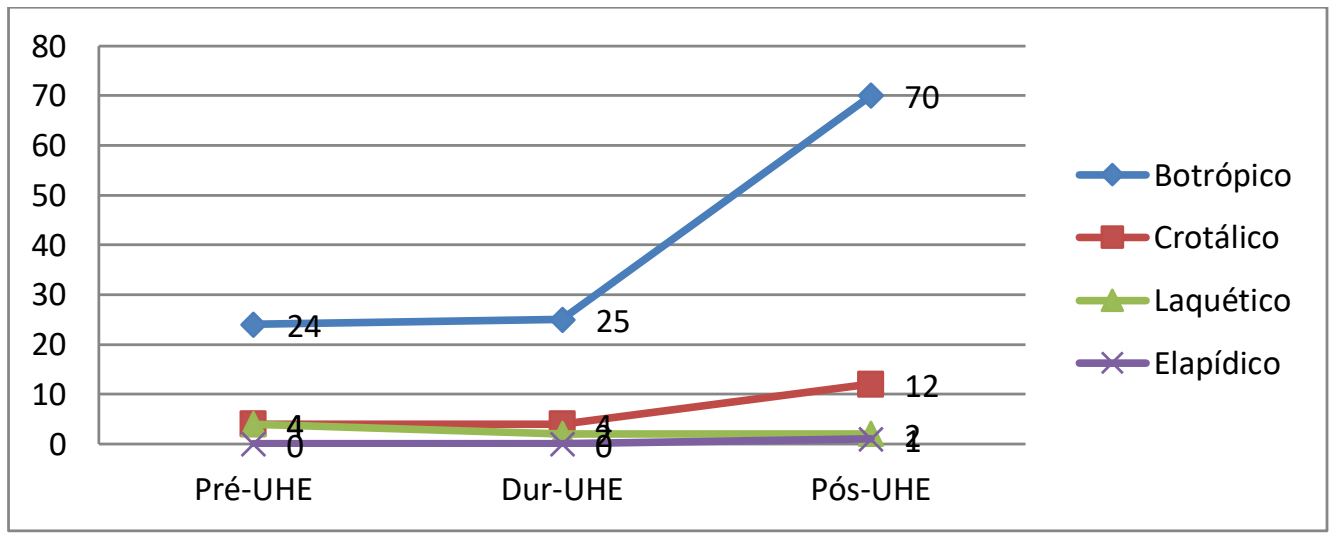

Figura1. Ocorrência dos Acidentes Ofídicos por período 
Sobre o período com maior ocorrência destaque para a fase após o enchimento do lago reservatório, este apresentando um acréscimo de $112 \%$ nos casos, em relação aos períodos anteriores, com destaque para os gêneros Botrópico (180\%) e crotálico (200\%) o mesmo ocorrendo em estudos com zoonoses e Dengue pesquisado por Gomes (2014), na mesma região onde o mesmo período apresentou significativos índices em relação aos demais, fato este que chama atenção para a instabilidade ambiental gerada por esses empreendimentos que podem durar décadas de acordo com o processo de maturação do lago e ambientação faunística, podendo afetar de forma direta no perfil epidemiológico da região (GOMES et al., 2016).

A temperatura mostrou-se um fator diretamente relacionado a incidência dos acidentes $(r=0.78)$, não podendo relacionar os ataques a baixa temperatura, haja vista a temperatura média local esteve acima dos 30 graus, fato devido a características climáticas regionais onde caracteriza-se pela presença de dois períodos bem definidos como chuvoso e seco, sendo o período chuvoso (novembro a fevereiro) e o de transição (março a junho) como os de maior relevância epidemiológica, característica esta que alinha-se ao período de colheita dos principais produtos agrícolas cultivados na região (arroz, milho, soja e feijão) que variam de janeiro a junho, favorecendo a grande inserção humana em áreas rurais potencializando o risco de acidentes (ALBUQUERQUE, 2002.,IBGE, 2016).
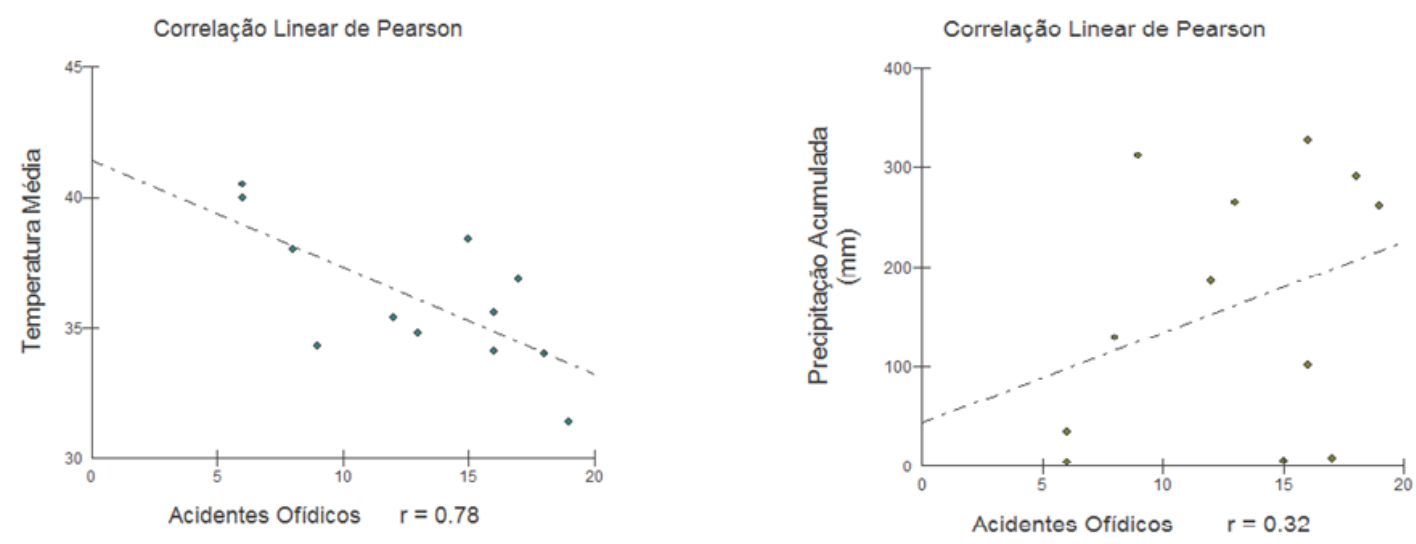

Figura 2. Análise de relação entre temperatura e precipitação acumulada com os casos de Acidente ofídicos no município de Estreito MA.

\section{CONSIDERACOES FINAIS}

No município de Estreito os acidentes ofídicos caracterizaram-se por apresentarem maior incidência no período após o enchimento total do lago reservatório (2011 a 2015), 
sendo homens em idade produtiva (20 a 59 anos) os mais acometidos, e o gênero botrópico o de maior incidência. Vale a pena destacar o grande aumento (200\%) dos casos de acidente com Crotálico em relação ao período durante as obras para o período após a conclusão da UHE.

Estudos em áreas sob influência direta de Usinas Hidrelétricas vem se tornando cada vez mais necessários, não apenas pelo imensurável impacto ambiental, social e epidemiológico gerado por esses empreendimentos, mas pela singularidade em que cada área manifesta nesse novo processo de territorialização seja humana como faunística associado a não capacidade das gestões locais em adequar a infraestrutura necessária a nova realidade local.

\section{REFERENCIAS}

AGÊNCIA NACIONAL DE ENERGIA ELÉTRICA - ANEEL. (2015). Disponível em: < www.aneel.gov.br $>$.

BORTOLETO ML. (2001). A implantação de Grandes hidrelétricas: Desenvolvimento. Discurso e impactos. Disponível em: < http://periodicos.ufes.br/geografares/article/view/1140 >. Acesso em 06.05.2016

CESTE. Consorcio Estreito - MA energia usina hidrelétrica Estreito (2016). Disponível em: $<$ http://www.uhe-estreito.com.br/ver secao.php?session id=71 >. Acesso em: 01.05.2016.

CHAVES, P R, LIRA E R. As relações sócio-territoriais na construção da usina hidrelétrica de Estreito-MAe sua (re) produção no espaço urbano das cidades de Carolina-MA e Filadélfia-TO. Cadernos de Pesquisa do CDHIS, 1(39), 2009.

DANCEY, Christine \& REIDY, John. (2006), Estatística Sem Matemática para Psicologia: Usando SPSS para Windows. Porto Alegre, Artmed.

FABIANA GOMES DE CASTRO FG; LEITE GB; PESSOA AM; PINTO RNL; JUNIOR NJ. (2015). Acidentes elapídicos no estado de Goiás - GO. Disponível em: $<$ http://seer.ucg.br/index.php/estudos/article/viewFile/4372/2507 >. Acesso em 08.05.2016.

FEARNSIDE. P.M. (2011). Desafios para midiatização da ciência na Amazônia: O exemplo da hidrelétrica de Belo Monte como fonte de gases de efeito estufa. In: A.Fausto Neto \& A. Ventura (eds.) A Midiatização da Ciência. UNISINOS. São Leopoldo. RS. (no prelo). Acesso em 03.08.2016.

FURTADO MFD; CALLEFFO MEV. (2008). A atuação do Instituto Butantan na Amazônia no século $X X$. Disponível em: < http://periodicos.ses.sp.bvs.br/scielo.php?script=sci arttext\&pid=S180976342008000200004\&lng=pt >. Acesso em 01.05.2016. 
GIONGO CR; MENDES JMR; SANTOS FK. (2015). Desenvolvimento. saúde e meio ambiente: contradições na construção de hidrelétricas. Serv. Soc. Soc.. São Paulo. n. 123. p. 501-522. jul./set. 2015. Disponível em: In<http://dx.doi.org/10.1590/0101-6628.034 >. Acesso em 30.04.2016.

GOMES H. JESUS. AG. SILVA JR. NJ. (2014). Perfil epidemiológico de zoonoses nos municípios afetados diretamente pela usina hidrelétrica Estreito (MA). Rev. Cereus. UnirG. Gurupi. TO. 2014a; 6(3): 158-71.

GOMES H; JESUS AG. (2016). Impacto da usina hidrelétrica estreito nos casos da dengue e leishmaniose no município de Carolina. Maranhão. Revista Movimenta ISSN:1984-4298. Disponível em: < http://www.revista.ueg.br/index.php/movimenta/article/view/4110/3146 >. Aceso em 30.04.2016.

IBGE. Instituto Brasileiro de Geografia e Estatística. 2016. Disponível em: http://cidades.ibge.gov.br/xtras/perfil.php?codmun=210405. Acesso em 10/07/2016.

MARIA M. V. ZANONI. JOSILÉIA A. ZANATTA. JEFERSON DIECKOW. AKEMI KAN. CARLOS B. REISSMANN. (2015). Emissão de metano por decomposição de resíduo florestal inundado. R. Bras. Eng. Agríc. Ambiental. v.19. n.2. p.173-179. 2015. Disponível em: <DOI: http://dx.doi.org/10.1590/1807-1929/agriambi.v19n2p173-179 >. Acesso em 03.08.2016.

MARQUES MSA. HERING SE. (2003). Acidentes por animais peçonhentos: serpentes peçonhentas. Medicina. Ribeirão Preto. 36: 480-489.abr. /dez.2003. Disponível em: < http://revista.fmrp.usp.br/2003/36n2e4/40animais peconhetos serpentes.pdf $>$. Acesso em: 01.05.2016.

MASSOLLI EC. (2013). Geração de energia elétrica e desenvolvimento sustentável: Uma análise das externalidades potencialmente geradas Pela uhe d Estreito-Ma. Editor: Juan Carlos M. Coll ( $\underline{\mathrm{CV}})$ ISSN: 1988-7833. Disponível em: < http://www.eumed.net/rev/cccss/26/empreendimentos-hidreletricos.html $>$. Acesso em 30.04.2016.

NOGUEIRA. PF. CABRAL. JBP. OLIVEIRA. SF. ROCHA. IR. (2015). Eutrofização no reservatório da UHE foz do rio claro. Revista do Departamento de Geografia - USP. Volume 30 (2015). p. 19 a 33. Acesso em: 03.08.2016.

SANCHES. F. FISCH. G. (2005). As possíveis alterações microclimáticas devido a formação do lago artificial da hidrelétrica de Tucuruí -PA. VOL. 35(1) 2005: 41 - 50. Acesso em 15.08.2016.

SILVA JC. GUIMARÃES CDO. PALHA MC. (2015). Perfil clínico-epidemiológico dos acidentes ofídicos ocorridos na ilha de Colares. Pará. Amazônia oriental. Semina: Ciências Biológicas e da Saúde. Londrina. v. 36. n. 1. p. 67-78. jan./jun. 2015. Disponível em: < DOI: 10.5433/1679-0367.201v36n1p67 >. Acesso em 01.05.2016.

SOUSA PC. (2011). Caracterização socioambiental e epidemiológica das. Comunidades da área diretamente afetada pela usina hidrelétrica Serra do Falcão - GO. Disponível em: $<$ http://repositorio.ufu.br/handle/123456789/3311 >. Acesso em 30.04.2016. 
TRINDADE. P.B.C.B. MENDONÇA. ASF. (2014). Eutrofização em reservatórios - Estudo de caso: reservatório de Rio Bonito (ES). Eng Sanit Ambient | v.19 n.3 | jul/set 2014 | 275282. Disponível em: < DOI: 10.1590/S1413-41522014019000000537>. Acesso em: 03.08.2016.

TUNDISI. RG. (2003). Recursos Hídricos. O Futuro dos Recursos \# 1. outubro de 2003. Acesso em: 03.08.2016. 